\title{
O dilema do enquadramento interpretativo: o caso das interações entre o movimento dos direitos animais e a grande mídia*
}

\author{
Matheus Mazzilli Pereira \\ \& Marcelo Kunrath Silva**
}

Resumo: Ativistas de movimentos sociais enfrentam um dilema em suas atividades de enquadramento interpretativo. De acordo com parte da literatura, imperativos morais são obstáculos para o imperativo estratégico e tal dilema tem origem na tensão entre esses dois polos. Este trabalho tem dois objetivos: (1) questionar e propor alternativas para essa caracterização dicotômica do dilema do enquadramento interpretativo; e (2) compreender os processos que geram diferentes respostas a esse dilema. Para isso, foram entrevistadas lideranças de quatro organizações de direitos animais em Porto Alegre; uma liderança de uma organização de direitos animais de São Paulo; e ativistas e jornalistas envolvidos na produção de notícias e artigos selecionados para análise em profundidade. Os resultados apontam que imperativos estratégicos e morais se complementam e são gerados por teorias nativas sobre como a transformação social ocorre e são moldados por pressões interativas, gerando as diferentes respostas ao dilema do enquadramento.

Palavras-chave: enquadramento, dilema, movimentos sociais, direitos animais, mídia corporativa.

\section{Introdução}

$\mathrm{N}$ o mês de junho de 2008, ativistas de direitos animais (ou, segundo sua autodenominação, abolicionistas) porto-alegrenses comemoraram a publicação de uma matéria no jornal Correio do Povo, reproduzindo a imagem de um anúncio outdoor por eles desenvolvido. O outdoor estampava a fotografia de um cavalo, que puxava carroças na cidade, caído e ensanguentado ao lado da frase "Prefeito: agora está em suas mãos o destino de um dos símbolos do Rio Grande do Sul". No anúncio, militantes mobilizam um dos símbolos da tradição gaúcha - o cavalo - em apoio à sanção de uma lei municipal que propunha a proibição do trânsito de carroças com tração animal na cidade de Porto Alegre (Correio do Povo, 2008).

Dois anos depois, uma ativista desse mesmo movimento publica na seção de artigos do jornal Zero Hora um texto no qual essas mesmas tradições são fortemente criticadas por serem utilizadas como justificativa para a exploração animal. Essa ativista afirma em seu artigo: "[...] tradição alguma é imutável sendo, para Montesquieu, a ignorância a mãe de todas as tradições". A militante segue expondo contradições das práticas dos gaúchos, que se indignam com determinadas formas

\footnotetext{
* Agradecemos à avaliação crítica dos pareceristas anônimos da Revista Sociedade e Estado, as quais contribuíram de forma significativa para a qualificação da argumentação desenvolvida no artigo.
}

** Matheus Mazzilli Pereira é bacharel em ciências sociais e mestre em sociologia pela Universidade Federal do Rio Grande do Sul, doutorando em sociologia pela mesma instituição de ensino. <matheus. mazzilli@gmail. com>.

Marcelo Kunrath Silva é doutor em sociologia e professor do Departamento de Sociologia da Universidade Federal do Rio Grande do Sul.<mksilva@ufrgs. br>. 
1. O conceito de enquadramento interpretativo (framing), que será apresentado de forma mais aprofundada ao longo do artigo, refere-se ao mecanismo central do processo de "definição da situação", tal como este é entendido na tradição do interacionismo simbólico. Através das molduras interpretativas (frames) acionadas no enquadramento interpretativo de uma situação determinada, os atores organizam e definem a sua percepção daquilo que experienciam. $\mathrm{O}$ conceito de frames, no Brasil, tem sido traduzido tanto como "quadro" quanto como "moldura". Optou-se por esta segunda tradução, uma vez que ela expressa de maneira mais fiel a analogia elaborada pelo formulador original deste conceito, Gregory Bateson (1972).

2. Para uma problematização da ênfase excessiva no alinhamento de molduras no estudo da ressonância, ver Hewitt e McCammon (2005). de exploração de alguns tipos de animais e defendem a exploração de outros em nome da tradição, descrevendo, posteriormente, um conceito incomum à linguagem cotidiana, mas central para os ativistas de direitos animais: senciência (Hassen, 2010).

Já em 2011, militantes de direitos animais figuram novamente nas páginas do jornal Zero Hora, relatando como compatibilizam sua escolha moral por hábitos veganos ao cotidiano na "terra do churrasco". Em busca da divulgação de sua identidade coletiva, os ativistas dão "dicas de sobrevivência" àqueles que desejam se tornar veganos e relatam casos pessoais vistos como capazes de romper estereótipos a respeito das práticas veganas. Assim, uma ativista relata, por exemplo, a surpresa de médicos e familiares ao constatarem que seu bebê, nascido após uma gestação vegana, estava em perfeitas condições de saúde (Luz, 2011). Em outra ocasião, militantes promoveram especialmente para uma profissional desse mesmo jornal um "churrasco vegano", com vegetais e "carne de soja", buscando demonstrar que a adoção do veganismo não implica no abandono do churrasco dominical entre amigos e parentes (Almeida, 2011).

Dessa forma, ativistas desenvolvem enquadramentos interpretativos ${ }^{1}$ distintos que ora defendem, ora se opõem, ora buscam a compatibilização de suas demandas às tradições gaúchas. Em outras palavras, militantes respondem diferentemente ao que se denomina de dilema do enquadramento interpretativo. Segundo a literatura, este dilema se estrutura a partir de duas premissas básicas. Primeiramente, se movimentos sociais oferecem algum tipo de desafio à cultura dominante e/ou às relações de poder estabelecidas, supõe-se que os símbolos que orientam sua ação se distanciem, em alguma medida, das concepções difundidas e aceitas pela maior parte da população ou da elite política. Em segundo lugar, a literatura alega que a possibilidade de que os interlocutores dos ativistas considerem o enquadramento apresentado pelos movimentos sociais como uma boa definição de "o que está acontecendo aqui" diminui se esse enquadramento não se aproximar, ao menos em parte, das molduras já entendidas como adequadas para esse interlocutor (Benford \& Snow, 2000; Noakes \& Johnston, 2005). Neste sentido, a ocorrência de um alinhamento de molduras interpretativas (frame alignment) seria fundamental para que determinado enquadramento interpretativo encontrasse ressonância, definindo seu potencial de convencimento, difusão e eficácia mobilizadora (Benford \& Snow, 2000; Snow et alii, 1986) $)^{2}$.

Essas duas premissas impõem, assim, um dilema básico de enquadramento aos movimentos sociais, resumido por Tarrow (2009) da seguinte maneira: 
Há um paradoxo na política simbólica dos movimentos sociais: entre desenvolver símbolos dinâmicos que criarão novas identidades e realizarão mudanças e oferecer símbolos que sejam familiares às pessoas e baseados em suas próprias culturas (Tarrow, 2009: 140).
Ou seja, o dilema do enquadramento interpretativo parece expressar uma tensão entre ruptura ou confrontação do estabelecido, importante para as transformações almejadas, bem como ressonância ou adaptação ao existente, práticas necessárias à aceitação pelos interlocutores do movimento.

Tradicionalmente, o dilema do enquadramento interpretativo tem sido caracterizado pela literatura como tensão entre imperativos estratégicos e morais. Esse artigo busca responder duas perguntas teóricas relacionadas a esse dilema: A caracterização do dilema do enquadramento como relação de soma-zero entre ideologia e estratégia é satisfatória para a compreensão da complexidade dos processos de enquadramento? O que leva diferentes organizações de movimentos sociais e ativistas a responderem diferentemente a um dilema comum? Para isso, o artigo apresenta uma discussão teórica sobre o tema, utilizando como ilustração casos de interação entre ativistas de direitos animais e membros da mídia corporativa investigados ao longo de uma pesquisa empírica realizada entre os anos de 2012 e 2013.

O movimento dos direitos animais propõe o diagnóstico de que animais devem ser considerados sujeitos de direitos inalienáveis, tais como o direito à vida e o direito à liberdade. Dessa maneira, as atuais relações entre animais humanos e não humanos seriam problemáticas, na medida em que os direitos dos animais seriam violados por práticas como o consumo de carne e derivados, o uso de vestimentas confeccionadas com peles, testes científicos com cobaias animais, entre outras (as chamadas práticas de exploração animal). Tendo em vista tal diagnóstico, ativistas propõem como prognóstico a abolição de todas as formas de exploração de animais não humanos. Isso significaria a adoção de hábitos veganos ${ }^{3}$ e a formulação de políticas públicas que garantiriam a preservação dos direitos animais. Dessa forma, tais ativistas se diferenciam de militantes do "bem-estar animal" - que buscam aprimorar as condições de vida de animais que são usados por seres humanos - e de ativistas da "proteção animal" - que buscam boas condições de vida para animais socialmente valorizados, tais como cães e gatos (Evans, 2010; Garner, 1998; Freeman, 2010; Sordi, 2011).

O desenho da pesquisa que fundamenta este artigo foi dividido em duas fases. $\mathrm{Na}$ primeira, buscamos identificar os principais dilemas de enquadramento vivenciados por ativistas de quatro organizações de direitos animais de Porto Alegre e de
3. O veganismo também é adotado por indivíduos com motivações não relacionadas ao diagnóstico dos direitos animais, assim como por indivíduos não formalmente engajados em organizações abolicionistas, mas em "movimentos culturais difusos" ou em esforços de "contracultura" (Abonizio, 2013; Cherry, 2006). 
uma agência de notícias focada em direitos animais sediada em São Paulo. Foram reunidos notícias e artigos relacionados ao ativismo abolicionista animal publicados nos dois maiores jornais do Rio Grande do Sul, bem como na agência de notícias citada anteriormente. Este material foi apresentado em entrevistas para os líderes das organizações estudadas, sendo utilizado como estímulo para que os respondentes avaliassem diferentes possibilidades de enquadramento em interações com a grande mídia. Tais entrevistas foram analisadas por um procedimento indutivo que buscou identificar e categorizar as molduras presentes em tais materiais; compreender a centralidade de tais molduras para a organização da experiência dos ativistas; identificar padrões organizacionais de avaliação de táticas de enquadramento; e compreender as justificativas utilizadas por militantes para defender ou criticar enquadramentos.

Na segunda fase da pesquisa, casos que representavam táticas de enquadramento identificadas na primeira fase da investigação foram selecionados para a análise de sua produção interativa. Ativistas e jornalistas envolvidos na produção desses materiais foram entrevistados. Tais entrevistas foram conduzidas e codificadas tendo-se como base as premissas da análise de discurso interacionista, que busca identificar os contextos interativos e os mecanismos que moldam processos de enquadramento em dada situação (Gill, 2000). Os entrevistados foram estimulados a refletir sobre as razões que os levaram a adotar determinada postura na situação em análise. O material foi codificado buscando-se isolar os mecanismos que operaram nessas interações. A codificação foi dedutiva e indutiva, na medida em que alguns mecanismos foram antecipados por hipóteses de pesquisa e outros foram identificados por meio da análise.

Esse trabalho está organizado da seguinte forma. A primeira parte do artigo apresenta a discussão teórica sobre imperativos estratégicos e morais na perspectiva do enquadramento interpretativo. São criticadas concepções que concebem imperativos morais como "obstáculos" para a ação estratégica. São propostas alternativas teóricas por meio da adaptação de conceitos já existentes como os de "ideologia" e "fabricações" e por meio do conceito de "tendências de enquadramento". Na segunda parte do artigo, são explorados os motivos pelos quais atores respondem diferentemente ao dilema do enquadramento. Defende-se que ativistas respondem a dilemas práticos de acordo com suas teorias nativas sobre transformação social, bem como respondendo a contextos interativos específicos. 


\section{Além da dicotomia entre estratégia e moralidade}

Ao longo das últimas décadas do século XX, a abordagem do enquadramento interpretativo ${ }^{4}$ foi paulatinamente incorporada às mais importantes teorias desenvolvidas dentro do campo de estudos de movimentos sociais, estabelecendo-se como dimensão central para a análise do confronto político (McAdam, McCarthy \& Zald, 1999; McAdam, Tarrow \& Tilly, 2001; Tarrow, 2009). Tal abordagem contribui para o debate sobre movimentos sociais ao enfatizar o papel diligente dos ativistas como produtores de interpretações contenciosas, a necessidade de alinhamento cognitivo para o engajamento, bem como a importância de disputas interpretativas para a emergência, o desenvolvimento e a resolução do confronto político (Benford, 1993; Benford \& Hunt, 1992; Benford \& Snow, 1992; McAdam, 1999; Silva, Cotanda \& Pereira, no prelo; Snow, 2004; Snow et alii, 1986; Snow \& Byrd, 2007).

No entanto, as propostas teóricas desenvolvidas originalmente por Robert Benford e David A. Snow sofreram críticas de diversos autores. A perspectiva do enquadramento interpretativo deu ênfase à ação estratégica dos ativistas ao mostrar que movimentos sociais buscam produzir mensagens que os ajudam a "mobilizar potenciais aderentes, conquistar o apoio dos observadores e desmobilizar antagonistas" (Snow \& Benford, 1988: 198, tradução nossa; Noakes \& Johnston, 2005; Westby, 2005). Embora Benford e Snow considerem que o enquadramento interpretativo é também um fenômeno tácito, discursivo e contencioso, os autores reconhecem que essa literatura "dedicou muito mais atenção empírica aos processos estratégicos associados ao enquadramento em movimentos" (Benford \& Snow, 2000: 624, tradução nossa). Críticas a essa abordagem "estratégica" podem ser sistematizadas em dois conjuntos de argumentos.

Por um lado, autores criticam a perspectiva do enquadramento interpretativo por ignorar que a cultura, em muitas ocasiões, influencia a ação social de forma tácita, pouco consciente e reflexiva (Mathieu, 2002; Johnston \& Alimi, 2012). Lilian Mathieu (2002), por exemplo, destaca que parte da formulação original de Erving Goffman (1986) se referia justamente a esse tipo de fenômeno em que a agência estratégica dos indivíduos é escassa, resumindo esse problema da seguinte maneira:

Ainda que Goffman estivesse interessado prioritariamente no enquadramento como atividade cognitiva largamente pré-reflexiva de atribuição de sentido (assim como em suas falhas) e concedesse apenas atenção secundária às molduras em si, o uso que Snow e seus colaboradores fazem desse aparelho conceitual desloca o interesse em direção a um trabalho reflexivo de redefinição das
4. Na revisão da literatura brasileira sobre movimentos sociais foram encontrados poucos trabalhos (Bertoncelo, 2009; Maciel, 2011; Penna, 2012; Prudencio \& Santos, 2011; Rothberg \& Berbel, 2010) que empregam o conceito de molduras interpretativas (incluindo-se outras traduções), todos bastante recentes. Destacam-se ainda os trabalhos de Jordão Horta Nunes (2013a e 2013b) como esforços pioneiros no sentido de desenvolver um tratamento mais sistemático do conceito de molduras interpretativas e de sua aplicação ao estudo dos movimentos sociais no Brasil. 
representações, na medida em que é consciente e tático. As molduras não aparecem mais tanto como o produto de uma atividade cognitiva, mas antes como esquemas de interpretação relativamente estáveis e rígidos, que tornam possível que certos sujeitos os manipulem de maneira coerente com seus interesses (Mathieu, 2002: 87, tradução nossa).

Como resposta a esta ênfase excessiva na possibilidade de manipulação consciente e/ou instrumental dos processos de enquadramento, Hank Johnston e Eitan Alimi (2012) propõem o resgate do conceito de molduras primárias de Goffman (1986) para a análise de movimentos sociais. Ao seguir a proposta original desse autor, o enquadramento interpretativo pode ser visto como processo que ocorre em camadas. A camada inferior e mais básica desse processo é caracterizada pelo enquadramento primário, através do qual indivíduos tendem a apreender sua experiência cotidiana de forma pouco reflexiva. Assim, segundo Goffman:

Cada moldura primária permite que seu usuário localize, perceba,
identifique e rotule um número aparentemente infinito de ocor-
rências concretas definidas em seus termos. O usuário provavel-
mente não está ciente das características organizadas dessas inter-
pretações e nem é capaz de descrevê-las, caso isso seja solicitado
e, mesmo assim, essas deficiências não impedem que ele as use
fácil e completamente (Goffman, 1986: 21, tradução nossa).

O viés estratégico inicialmente apresentado pela literatura do enquadramento interpretativo também é criticado por ignorar que as mensagens desenvolvidas por movimentos sociais tenham uma importância normativa para os ativistas e que, portanto, a cultura pode influenciar a ação social por meio de valores que estabelecem seus fins. Ou seja, argumenta-se que as molduras interpretativas da ação coletiva não são meros meios para a obtenção de resultados, elas têm uma importância axiológica na organização da experiência dos indivíduos (Gillan, 2008; Oliver \& Johnston, 2005; Maia, 2009; Steinberg, 1998; Vaisey, 2008a). Para solucionar esse problema teórico, autores têm criado ou resgatado uma série de conceitos para se referir às convicções normativas ou ao sistema axiológico dentro do qual ativistas cunham suas mensagens, tais como: molduras orientadoras (Gillan, 2008), campos discursivos (Steinberg, 1998) e ideologia (Oliver \& Johnston, 2005).

O que se percebe a partir dos argumentos expostos acima é que a crítica ao viés estratégico-instrumental no tratamento dos processos de enquadramento interpretativo dá origem a propostas que, a partir de conceitos diversos, direcionam o foco ora na dimensão tácita da ação, ora em sua dimensão axiológica. Estabelece-se, assim, uma falta de clareza teórica persistente apontada pela literatura como um 
dos desafios mais importantes da atual agenda de pesquisa dentro desse campo de debates (Snow et alii, 2014).

Autores têm tentado solucionar esse problema com abordagens sintéticas, que buscam incluir em um mesmo modelo aspectos morais e estratégicos da ação (Rohlinger, 2002; Vaisey, 2008a; Westby, 2005; Zhao, 2010). Algumas dessas abordagens, no entanto, tendem a apresentar modelos dicotômicos, cujos polos ideologia/identidade e estratégia são vistos como elementos antagônicos que competem pela orientação da ação dos indivíduos, sendo tratados como se fossem forças inversamente proporcionais ${ }^{5}$. Aspectos morais são vistos, assim, como "obstáculos" para a ação estratégica e, portanto, qualquer incremento da postura ideológica/identitária geraria, necessariamente, um decréscimo nas considerações estratégicas dos ativistas (Rohlinger, 2002; Westby, 2005; Zhao, 2010).

Ao buscarem romper com abordagens dicotômicas, autores criticam a contraposição entre estratégia e ideologia, na medida em que ela obscurece a compreensão de que toda ação é, em algum nível, ao mesmo tempo ideológica e estratégica. Dessa forma, a aplicação desse esquema dicotômico pode obscurecer o fato de que, por um lado, as ideologias podem ser estrategicamente mobilizadas para o alcance de determinados fins estipulados para a ação coletiva. Por outro, esse esquema pode dificultar a percepção de que, subjacentes a ações, aparentemente apenas estratégicas e voltadas à obtenção de resultados imediatos, há valores e convicções (Polletta, 1997; 2004). Assim, táticas como um todo - e não apenas de enquadramento - não são meios neutros para ativistas, mas "representam importantes rotinas, moralmente e emocionalmente salientes nas vidas das pessoas" (Jasper, 1997: 237, tradução nossa).

Baseados nessas críticas, como é possível classificar os diferentes tipos de molduras interpretativas?

\section{Classificando as molduras: \\ a adequação imaginada das categorias}

Este artigo busca apresentar um modelo de classificação das molduras afastado da dicotomia entre estratégia e ideologia, baseado na proposta original de Goffman (1986) de classificação das molduras, de acordo com seu papel na organização da experiência dos atores. Dito de outra forma, o modelo proposto classifica as molduras de acordo com a sua adequação imaginada (pelos atores sociais) para a classificação das situações.

5. Dingxin Zhao (2010), por exemplo, argumenta que um aumento das capacidades organizativas permite um incremento das considerações estratégicas das organizações e um "desprendimento" em relação às ideologias. Já David Westby (2005) argumenta que, de acordo com o nível de "saliência ideológica”, organizações podem transitar entre diversas combinações entre "ideologia" e "imperativo estratégico". 
Esse modelo segue a tendência de síntese teórica entre as diversas formas de influência da cultura na ação social (Vaisey, 2008; Westby, 2005; Zhao, 2010). De forma análoga ao que propõe Zhao (2010), defende-se que a cultura pode afetar a ação coletiva de maneiras distintas: como uma "caixa de ferramentas" (a partir das quais atores podem selecionar símbolos de acordo com suas necessidades); como "scripts" ou "valores" (com forte carga normativa); e como "instintos" (pouco percebidos pelos atores). Ao se afastar de premissas dicotômicas, porém, esses elementos não são vistos como forças inversamente proporcionais, o que não significa que atores não estabeleçam julgamentos acerca da moralidade e da efetividade de certas formas de uso de molduras interpretativas (assunto tratado nas próximas seções).

O modelo proposto busca abrigar sob a rubrica do enquadramento interpretativo e sob os pressupostos do interacionismo simbólico os diversos tipos de molduras que influenciam diferentemente a ação dos ativistas e das organizações de movimentos sociais. Isso ocorre na medida em que se defende que a proposta original de Goffman (1986) busca conciliar o caráter tácito e estruturado da experiência dos atores à possibilidade de que atores utilizem os sentidos estruturados tendo em vista seus interesses.

O conceito de molduras primárias de Goffman (1986) é adotado em seu sentido original, como categorias utilizadas de forma tácita pelos atores em sua definição das situações. Essas categorias influenciam os atores sociais sem que eles ao menos percebam essa influência, deixando clara a atuação da cultura em forma de "instinto" na ação social. No caso do ativismo em defesa dos direitos animais, por exemplo, é provável que uma série de concepções culturais acerca das relações entre natureza, seres humanos e animais não humanos afete as formas pelas quais ativistas enquadram sua luta (essa dimensão do fenômeno, no entanto, não foi objeto de análise).

O conceito de molduras ideológicas baseia-se no conceito de ideologia tal como definido por Pamela Oliver e Hank Johnston (2005). Ele se refere às categorias vistas pelos ativistas como as definições mais adequadas para a interpretação e avaliação moral das situações a que se referem, definindo a luta dos ativistas e os problemas por eles identificados. Molduras ideológicas, em outras palavras, respondem à pergunta "o que está acontecendo aqui?", quando voltadas para as situações que estão no foco dos ativistas. Essas categorias têm uma importância normativa para os militantes, não podendo ser completamente esquecidas. No caso do ativismo em defesa dos direitos animais, as principais molduras ideológicas do movimento giram em torno da ideia de que a defesa dos animais deve estar baseada em uma crítica ao 
especismo e na ideia de que a senciência é único critério válido para a definição da fronteira entre os indivíduos portadores e não portadores de direitos, o que tornaria os animais sujeitos de direito.

É proposto, ainda, um conceito análogo ao de molduras ideológicas, no intuito de conciliar o modelo proposto a outro importante debate sobre a dimensão simbólica da ação coletiva: o debate sobre as identidades coletivas tal como proposto por Melucci (1995). Molduras identitárias são as categorias vistas pelos ativistas como as definições mais adequadas para a identidade coletiva e para as práticas do grupo ao qual os militantes estão vinculados. Essas molduras também têm uma importância normativa para os ativistas, não podendo ser completamente esquecidas. Porém, ao invés de responder à pergunta "o que está acontecendo aqui?" - identificando problemas sociais - essas categorias respondem mais às perguntas "quem somos nós?" e "o que fazemos?". No caso dos direitos animais, o veganismo é o centro da identidade coletiva do movimento, sendo a descrição desse conjunto de hábitos, tal como concebido pelos militantes, a principal moldura identitária verificada. Os conceitos de molduras ideológicas e de molduras identitárias buscam enfatizar a influência em forma de "script" ou de "valores" da cultura na ação coletiva.

Ainda, como Goffman (1986) defende, algumas categorias podem ser vistas como apropriadas para a definição das situações, sendo, porém, consideradas menos relevantes para essa tarefa. Neste trabalho é proposto o conceito de molduras periféricas para a descrição de tais categorias. Essas molduras são vistas como definições adequadas das situações, mas não são vistas como as mais adequadas para a sua definição, quando comparadas aos dois primeiros tipos citados. Essas categorias não detêm, portanto, a importância normativa que molduras ideológicas e identitárias detêm para os ativistas. No caso do ativismo em defesa dos direitos animais, argumentos que giram em torno da preservação ambiental são vistos, por parte dos ativistas, como enquadramentos periféricos. Estes ativistas alegam que o veganismo, de fato, tem impactos positivos para a preservação do meio ambiente (é uma classificação adequada da crítica moral). Esses mesmos militantes defendem, no entanto, que, mesmo se os impactos do veganismo fossem negativos em termos ambientais, eles ainda considerariam o veganismo um conjunto apropriado e ético de práticas, na medida em que o seu foco é o combate ao especismo.

Por fim, este trabalho adota outra definição conceitual idêntica à proposta por Goffman (1986): a de fabricações. Fabricações são classificações das situações vistas pelos próprios atores sociais que as defendem frente a um interlocutor como inapropriadas tanto moral quanto cognitivamente para a definição das situações em questão, mas que são utilizadas para que os atores sociais alcancem determinados 
6. As demais categorias podem, no entanto, também ser vistas como categorias socialmente disponíveis para o uso dos atores, apesar de deterem características especiais tais como a aplicação tácita ou a importância axiológica para os indivíduos.

\section{No caso do} movimento pelos direitos animais, por exemplo, é possível citar a controvérsia em torno da questão da preservação ambiental. Se, como visto anteriormente, as molduras que giram em torno da defesa do meio ambiente são vistas por boa parte dos militantes como molduras periféricas, outros ativistas defendem que a defesa do meio ambiente é uma questão tão central para a defesa dos direitos animais quanto à crítica ao especismo. $\mathrm{O}$ argumento desenvolvido pelos ativistas, nesse caso, sustenta que, na medida em que o meio ambiente é o habitat dos animais, qualquer ação que o prejudique é uma ação especista, na medida em que submete interesses básicos dos animais (a garantia do local de sobrevivência) aos interesses humanos. objetivos em uma interação. Nesse caso, a influência da cultura como "caixa de ferramentas" na ação coletiva fica mais evidente (Swidler, 1985; 2008). . No caso do ativismo em defesa dos direitos animais, a tradição, quando utilizada em um enquadramento, é vista como uma fabricação por boa parte dos militantes, na medida em que a ideologia do movimento traz em si uma crítica a práticas especistas tradicionais, levando ativistas a defenderem a modificação das tradições no que tange à defesa dos direitos animais.

As molduras interpretativas da ação coletiva comportariam todos esses tipos de molduras, sendo caracterizadas por seu uso em interações com o intuito de atingir os diversos objetivos dos movimentos sociais. É necessário ressaltar, no entanto, que a definição sobre quais categorias podem ser vistas como molduras ideológicas/ identitárias ou periféricas tende a estar em disputa dentro de um movimento social. Como ressaltam diversos autores, as interpretações não são estáticas, sendo melhor compreendidas quando vistas como processos de construção social por meio de negociações de sentido (Benford, 1997; Melucci, 1995)7.

Se tomarmos essa nova classificação das molduras, baseada na adequação imaginada das categorias e no papel das categorias para a organização da experiência, a dicotomia entre ideologia e estratégia pode ser superada e as diversas formas de influência da cultura na ação coletiva podem ser compatibilizadas. Como isso pode afetar, teoricamente, a percepção a respeito do dilema do enquadramento?

\section{Compreendendo os dilemas: \\ as tendências de enquadramento}

Uma vez que a dicotomia ideologia-estratégia é questionada, como é possível reinterpretar o dilema do enquadramento? Neste trabalho, propõe-se que esse dilema seja repensado como tensão estabelecida entre ativistas de movimentos sociais a respeito da aceitabilidade e da eficácia do uso ou do privilégio do uso de determinados tipos de molduras interpretativas em detrimento de outros.

Ao longo da pesquisa empírica junto ao movimento dos direitos animais, foi possível identificar que diferentes organizações apresentam tendências distintas de utilização e combinação de determinados tipos de molduras nos seus processos de enquadramento interpretativo, o que se denomina aqui de tendência de enquadramento interpretativo. Três tipos básicos de tendências de enquadramento interpretativo podem ser descritos: a tendência conceitual, a tendência retórica e a tendência identitária (Quadro 1). 
QUADRO 1

TENDÊNCIAS DE ENQUADRAMENTO INTERPRETATIVO

\begin{tabular}{|l|l|l|l|}
\cline { 2 - 4 } \multicolumn{1}{l|}{} & \multicolumn{1}{c|}{ Molduras ideológicas } & Molduras identitárias & \multicolumn{1}{c|}{$\begin{array}{c}\text { Molduras periféricas e } \\
\text { fabricações }\end{array}$} \\
\hline $\begin{array}{l}\text { Tendência conceitual de } \\
\text { enquadramento }\end{array}$ & Exposição necessária & $\begin{array}{l}\text { Exposição desnecessária, } \\
\text { mas positiva se relacionada } \\
\text { à ideologia }\end{array}$ & $\begin{array}{l}\text { Rejeição ou utilização em } \\
\text { segundo plano }\end{array}$ \\
\hline $\begin{array}{l}\text { Tendência retórica de } \\
\text { enquadramento }\end{array}$ & $\begin{array}{l}\text { Ocultação ou exposição de } \\
\text { acordo com aceitação }\end{array}$ & $\begin{array}{l}\text { Ocultação ou exposição } \\
\text { seletiva de acordo com } \\
\text { aceitação }\end{array}$ & $\begin{array}{l}\text { Utilização de acordo com a } \\
\text { aceitação }\end{array}$ \\
\hline $\begin{array}{l}\text { Tendência identitária de } \\
\text { enquadramento }\end{array}$ & $\begin{array}{l}\text { Exposição desnecessária, } \\
\text { mas positiva }\end{array}$ & Exposição necessária & $\begin{array}{l}\text { Rejeição ou utilização em } \\
\text { segundo plano }\end{array}$ \\
\hline
\end{tabular}

Organizações e ativistas que se guiam por uma tendência conceitual de enquadramento procuram utilizar em todas as interações nas quais estão inseridas as categorias vistas, as molduras ideológicas do movimento, que apresentam novos conceitos e fornecem novos diagnósticos que problematizam as situações. Em relação às molduras periféricas e às fabricações, ativistas ora recusam sua aplicação, ora as combinam com suas molduras ideológicas, mas colocando-as em segundo plano (principalmente quando vislumbram alguma relação lógica entre as proposições). A utilização de molduras identitárias pode ocorrer, mas sempre de forma associada ao problema social identificado pelas molduras ideológicas. Assim, militantes que seguem essa tendência não orientam seu enquadramento visando maximizar a possibilidade de aceitação do outro, podendo até mesmo valorizar uma reação negativa do interlocutor. A sua adaptação ao outro se dá de forma a maximizar o poder de crítica à realidade social e à capacidade de reflexão do interlocutor em direção a essa crítica, podendo ser descrita como uma adaptação crítica ao outro.

No caso do ativismo por direitos animais, ativistas em que essa tendência é observada buscam sempre construir seu enquadramento em torno dos principais argumentos éticos em defesa dos direitos animais, optando sempre pela crítica aos hábitos especistas do interlocutor, mesmo que essa tática gere um afastamento inicial do outro, o que é, em muitos casos, até mesmo valorizado. Esses ativistas buscam evitar, na maior parte das ocasiões, a utilização de enquadramentos vistos como diferentes ou distantes daqueles avaliados como centrais para a definição da luta dos direitos animais, mesmo que a utilização desses enquadramentos possa aproximar temporariamente um interlocutor ao movimento. A defesa de identidades e de práticas está, normalmente, associada à constatação de um problema que é por elas respondido, o que pode ser resumido na ideia: "sou vegano, porque me oponho ao especismo". 
Já organizações e militantes que se orientam por uma tendência retórica de enquadramento procuram utilizar aquelas categorias que, segundo sua avaliação, têm o maior potencial imediato de compreensão e aceitação positiva por parte do interlocutor - em outras palavras, uma maior ressonância. Nesse caso, quando as molduras ideológicas forem vistas como incompatíveis com a aceitação imediata do outro, elas serão propositadamente ocultadas pelos atores, sendo substituídas por molduras periféricas ou fabricações consideradas pelos ativistas como relevantes para seu interlocutor. Nos casos em que interlocutores se mostrem mais receptivos às molduras ideológicas do movimento, no entanto, ativistas podem optar por expô-las direta ou indiretamente. Em relação às molduras identitárias, militantes buscam expor aspectos vistos como valorizados por seu interlocutor e ocultar aqueles vistos como rejeitados. Nesse sentido, o enquadramento se orienta sempre pela possibilidade de aceitação do outro, podendo ser compreendido como uma adaptação cooperativa ao outro.

Essa tendência se manifesta na militância por direitos animais em ativistas que buscam formular seus argumentos visando transformar seus interlocutores em aliados, adaptando-se cooperativamente a eles ou ao contexto social no qual estão inseridos, mesmo que isso resulte em um afastamento temporário de argumentos considerados centrais para a defesa da proposta dos direitos animais. Isso ocorre, na medida em que ativistas identificam um contexto no qual argumentos tais como a defesa da tradição ou a defesa do meio ambiente são mais valorizados e estão mais difundidos socialmente em comparação àqueles que buscam defender a ideia de direitos aplicada ao caso dos animais.

Por fim, ativistas e organizações que se orientam por uma tendência identitária de enquadramento buscam utilizar em todas as interações nas quais estão inseridas as suas molduras identitárias como um todo, que apresentam uma identidade legítima que deve ser reconhecida e compreendida pelos outros. Em relação às molduras ideológicas, ativistas buscam apenas utilizá-las quando vislumbram possibilidades de fala (como espaço para uma conexão lógica entre identidade e ideologia), mas não necessariamente quando antecipam recepção positiva. Em relação às molduras periféricas e às fabricações, militantes ou recusam sua aplicação, ou as aplicam em segundo plano em relação a suas molduras identitárias. Assim, militantes que seguem essa tendência não orientam seu enquadramento visando maximizar a possibilidade de aceitação imediata do outro, mas buscando expor sua identidade coletiva, de forma a construir sua legitimidade.

No caso da militância pelos direitos animais, ativistas que se identificam com essa tendência de enquadramento buscam construir seu enquadramento baseando-se na 
descrição de suas práticas tais como os próprios veganos as vivenciam e concebem, assim como na tentativa de demonstração da viabilidade do veganismo, seja pela exposição de argumentos científicos que defendem a viabilidade nutricional dessas práticas, pela divulgação de alternativas veganas de consumo ou pela descrição de pratos veganos como saborosos. Ativistas identitários veem como desejável, porém não necessária, a associação do veganismo à luta antiespecista, podendo estar explícita, em alguns casos, a conexão entre veganismo e escolhas éticas e, em outros casos, essa conexão estar completamente ausente do enquadramento proposto.

Dessa forma, o dilema do enquadramento pode ser compreendido como impasse entre a adoção e a defesa de uma tendência de enquadramento interpretativo frente às possibilidades existentes. Essa sistematização conceitual, no entanto, resolve apenas parte do problema. Se movimentos sociais têm à sua disposição categorias com características tão variadas, o que os leva a adotar umas em detrimento de outras?

A ideia de tendência é um indicativo da resposta proposta a essa questão. Tendências são predisposições de indivíduos ou grupos a agir de determinada maneira frente a determinadas situações que, no entanto, não necessariamente se confirmam na interação efetiva. Como destaca Vaisey (2008a; 2008b), a opção de um ator por determinada linha de ação frente a diversas alternativas deve ser compreendida como o resultado da dinâmica entre, por um lado, valores e preconcepções introjetadas e, por outro, pressões interativas. Logo, duas questões devem ser respondidas para a compreensão das respostas ao dilema do enquadramento interpretativo: o que gera a tendência de um ator a considerar determinados tipos de molduras como mais aceitáveis ou efetivas e de, assim, defender o seu uso em interações que ocorrerão, dando origem a resposta prévia ao dilema? E o que pode reforçar ou modificar essa resposta modular a esse dilema, ou seja, a escolha por uma tendência de enquadramento, em interações sociais reais, dando origem à resposta efetivamente observada ao dilema?

\section{Resposta ao dilema do enquadramento interpretativo}

As respostas oferecidas pela literatura para essas questões, baseadas em conceitos tais como os de "saliência ideológica" (Westby, 2005) e de "capacidade organizativa" (Zhao, 2010), estão fortemente influenciadas pela dicotomia entre estratégia e ideologia, criticada nesse artigo. De forma alternativa, propõe-se uma solução baseada no conceito de "tendências de enquadramento interpretativo" que, como dito anteriormente, conduz à necessidade de um modelo que explique, ao mesmo 
tempo, a constituição de preferências prévias de enquadramento por parte dos atores e a possibilidade de que dinâmicas interativas os levem à formulação de enquadramentos efetivos que, eventualmente, contrariem essas tendências.

\section{Teorias nativas da transformação social}

Na medida em que movimentos sociais buscam, de alguma maneira, transformar a sociedade, é possível imaginar que suas teorias sobre como o processo de mudança social ocorre possa impactar suas decisões. Nossos dados sugerem que tais teorias moldam as percepções dos ativistas sobre o que é "moralidade" e "estratégia". Isso ocorre na medida em que diferentes teorias impõem diferentes objetivos de curto prazo para os militantes que podem ser alcançados por diferentes táticas.

Alguns militantes acreditam que a transformação social se inicia quando há uma mudança na consciência da população. De acordo com tal teoria, a transformação dos valores de uma sociedade leva à transformação de suas práticas, leis e instituições. Dessa forma, a mudança de valores dos interlocutores se torna o principal objetivo de curto prazo dos ativistas. Tais militantes são fortemente influenciados por teóricos como Gary Francione (2007) e definem, por exemplo, as reformas de bem-estar como uma verdadeira "pedra no caminho" do movimento abolicionista, pois dificultariam a "conscientização" da população ao sugerir que, se fortemente regulada, a exploração animal pode ser considerada como moralmente aceitável (Evans, no prelo).

A estratégia construída a partir dessa teoria nativa, portanto, obedece à lógica de "construir, atrair e conquistar". Indivíduos deveriam inicialmente estar convencidos sobre o problema do especismo. Após esse processo, mais pessoas se tornariam veganas e resultados práticos seriam produzidos a partir dessa transformação. Nesse cenário, a defesa da tendência conceitual de enquadramento pode ser vista como a melhor estratégia já que é vista como a mais efetiva para produzir "choques morais" nos interlocutores (Jasper \& Poulsen, 1995).

De acordo com essa teoria nativa, a tendência conceitual é também a alternativa moral mais aceitável, na medida em que ativistas argumentam que essa é a tática mais comprometida com as normativas éticas da libertação animal. Tais imperativos éticos aparentemente se tornam centrais por causa de seu papel imaginado no processo de transformação social.

Outros ativistas, no entanto, discordam de tal teoria. De acordo com eles, a transformação social ocorre de acordo com a mudança de práticas da sociedade. Tais 
mudanças práticas fariam com que moralidades se adaptassem às novas rotinas. Nesse caso, pessoas são vistas como motivadas por interesses práticos e econômicos e não por normas e valores. Dessa forma, a luta pelas mudanças práticas vistas como possíveis no contexto atual se torna o principal objetivo de curto prazo dos militantes, influenciados por teóricos como David Stzybel (2007) e Carlos Naconecy (2009), a defenderem, por exemplo, que regras que garantam o bem-estar animal são "degraus" que ajudam a construir a abolição do especismo por meio de pequenas reformas que podem ser ampliadas pela construção de precedentes legais e pela formação de redes com indivíduos influentes (Evans, no prelo).

Em geral, no caso dos direitos animais, como o contexto no qual a militância ocorre é visto como não favorável à perspectiva abolicionista, tais mudanças práticas podem ser mais facilmente conquistadas pela formação de alianças, pela negociação, pela adaptação ao contexto e pela imposição de obstáculos aos adversários. Isso pode exigir um afastamento temporário dos ativistas em relação às molduras ideológicas e identitárias do movimento.

A estratégia construída a partir dessa teoria obedece à lógica "conquistar, construir e atrair". Leis proibindo ou dificultando práticas de exploração animal diminuiriam a exploração no contexto atual e tornariam tais práticas menos familiares e justificáveis. Dessa forma, indivíduos identificariam o problema do especismo e adeririam ao veganismo. Nesse caso, a defesa da tendência retórica de enquadramento é vista como a melhor estratégia, na medida em que a adaptação de molduras e objetivos é vista como a tática capaz de levar a mudanças práticas em um ambiente hostil.

De acordo com tal teoria, a tendência retórica de enquadramento é também a mais correta do ponto de vista moral, na medida em que representaria maior foco nos interesses imediatos dos animais. Provavelmente tais interesses se tornam centrais do ponto de vista moral pelo importante papel que mudanças práticas para os animais têm nessa teoria nativa.

Por fim, uma terceira teoria nativa sobre transformação social pode ser observada no movimento dos direitos animais. De acordo com tal teoria, mudanças em identidades e práticas pessoais seriam as responsáveis pela identificação de problemas e pela produção de resultados práticos que beneficiem os animais. Dessa forma, a conquista de novos veganos se torna o objetivo de curto prazo mais importante para os militantes.

A lógica tática construída a partir dessa teoria obedece à máxima "atrair, construir e conquistar". Primeiramente, indivíduos se tornariam veganos por qualquer moti- 
vação, não necessariamente relacionada a direitos animais, tais como saúde e meio ambiente. Através do contato com práticas veganas e redes de indivíduos com a mesma identidade, os novos veganos iriam paulatinamente se familiarizar com o diagnóstico do especismo. A partir dessa nova moralidade e identidade, mudanças práticas poderiam ocorrer tanto em paralelo - como efeito do boicote vegano quanto futuramente pelo fortalecimento da luta. Nesse cenário, a defesa da tendência identitária de enquadramento é vista como a melhor estratégia, na medida em que é observada como aquela capaz de quebrar estigmas em relação a veganos e atrair indivíduos para o veganismo.

De acordo com tal teoria, a tendência identitária de enquadramento é também a tendência mais aceitável do ponto de vista moral, na medida em que o comprometimento pessoal com as práticas veganas se torna um aspecto central. Isso provavelmente ocorre pelo papel que a transformação pessoal e identitária assume dentro dessa teoria.

Em suma, ativistas desenvolvem diferentes teorias sobre a mudança social. Em decorrência de tais teorias, militantes estabelecem diferentes objetivos de curto prazo para a militância. Tendo em mente tais objetivos, determinada tendência de enquadramento se torna ao mesmo tempo mais efetiva estrategicamente e aceitável moralmente. Dessa forma, teorias sobre a transformação social moldam preferências pessoais e organizacionais para a resolução de dilemas. Mas ativistas nem sempre agem de acordo com tais preferências.

\section{Mecanismos interativos}

Se levarmos a sério os pressupostos interacionistas da abordagem do enquadramento interpretativo, é necessário considerar que mesmo configurando preferências de enquadramento, as teorias sobre a transformação social estão sempre sujeitas à negociação em um processo de interação social, na medida em que esta é dotada de mecanismos próprios e contingências que influenciam decisivamente a ação efetiva de enquadramento dos atores sociais (Benford, 1997; Benford \& Snow, 2000). Segundo Goffman (2002), em uma interação social, atores estão sempre em busca da resposta à pergunta "o que está acontecendo aqui?". A dinâmica da busca por essa resposta em uma interação pode ser resumida, da seguinte maneira:

Quando um indivíduo chega à presença de outros, estes, geralmente, procuram obter informação a seu respeito ou trazem à baila a que já possuem. [...] A informação a respeito do indivíduo serve para definir a situação, tornando os outros capazes de conhecer 
antecipadamente o que ele esperará deles e o que dele podem esperar. Assim informados, saberão qual a melhor maneira de agir para dele obter uma resposta adequada (Goffman, 2002: 1).

Essa breve definição apresenta vários fatores relevantes para a caracterização de uma interação. Em primeiro lugar, em uma interação social atores buscam conhecer as características de seu interlocutor, o que pode ocorrer de diversas maneiras. Essa definição mostra, ainda, outra dimensão importante das interações sociais, que deve ser afetada diretamente pelas combinações de lógicas de ação: indivíduos sempre têm alguma intenção nas interações ${ }^{8}$. Espera-se, ainda, que indivíduos regulem sua representação (as formas de agir e enquadrar as situações para o outro) de acordo com a reação esperada do interlocutor, de maneira a conquistar seus objetivos. Dessa maneira, no que tange ao enquadramento interpretativo, a antecipação do impacto do enquadramento no interlocutor é uma dimensão fundamental das interações sociais ${ }^{9}$.

As dimensões interativas não se resumem, no entanto, às informações construídas e obtidas em uma interação. As definições das situações, por exemplo, não se definem totalmente nessa dinâmica. Segundo Goffman (1959), a repetição de comportamentos análogos em situações diversas leva atores a imaginarem uma congruência entre elas, reunindo-as sob uma mesma categoria abstrata, o que ele denomina de idealizações. Ao fazer isso, atores estabelecem comportamentos esperados e pré-estabelecidos para essas interações, guiando-se por essas normas pré-estabelecidas em interações futuras. De forma análoga, Johnston (2000; 2005) defende a importância das situações de fala para a análise do enquadramento dos ativistas, definidas como um "um episódio de interação delimitado no qual há regras específicas sobre o que deve e o que não deve ser dito" (Johnston, 2000: 222, tradução nossa). Ainda, quando determinadas rotinas de interação se repetem, ou seja, indivíduos repetem suas formas de agir e enquadrar as situações constantemente diante de um mesmo conjunto de interlocutores, não só as situações se tornam idealizadas, mas os indivíduos passam a ser vistos a partir de padrões de comportamentos esperados para essas interações: os papéis sociais (Goffman, 2002; Johnston, 2000; 2005) ${ }^{10}$.

Dessa forma, podem ser apontados cinco mecanismos interativos que conformam as respostas dos ativistas e das organizações de movimentos sociais ao dilema do enquadramento interpretativo: a atribuição de características aos interlocutores; a antecipação do impacto do enquadramento interpretativo; o estabelecimento de intenções; a adequação à situação de fala; e o desempenho de um papel social ${ }^{11}$.

A operação destes mecanismos pode ser exemplificada por uma breve análise das interações entre ativistas de direitos animais e representantes da grande mídia que
8. Na tentativa de delimitar uma técnica para a análise de molduras, Hank Johnston (2000; 2005) também reconhece a importância da análise da intenção do ator em uma interação.

9. É importante ressaltar, nesse ponto, que todos os objetivos requerem uma representação Assim, as dinâmicas interativas não afetam apenas aqueles que orientam seu enquadramento de acordo com a aceitação imediata da plateia. Dizer que um indivíduo tende a valorizar suas molduras ideológicas e identitárias não significa dizer que ele ignorará as dinâmicas interativas na medida em que elas irão afetar decisivamente a forma como essas molduras serão expostas, a necessidade de combinação dessas molduras com outras e até mesmo os tipos de interação que esses atores procuram estabelecer ou evitar. Ainda, indivíduos podem esperar uma reação negativa do interlocutor e, intencionalmente, provocá-la. Ou seja, a influência do outro em uma interação e a orientação da representação pelo outro não significa necessariamente uma adaptação em direção à aceitação do outro. Nesse 
sentido é importante a distinção entre

a "adaptação

cooperativa

ao outro" e a

"adaptação crítica ao outro".

10. Uma discussão teórica mais aprofundada sobre a relação entre os conceitos de "papel social" e "identidade coletiva" se mostra necessária, embora fuja ao escopo desse trabalho.

11. Não se pretende, neste trabalho, listar de forma exaustiva os mecanismos presentes em interações sociais. Em outros casos, novos mecanismos devem ser identificados e os mecanismos aqui apontados podem perder importância analítica.

12. Nenhum caso analisado em profundidade nessa seção apresenta como característica central a imposição de obstáculos interativos à utilização de determinada combinação preferencial de lógicas de ação. Exemplos desse tipo de caso foram, no entanto, observados ao longo da pesquisa como em um caso no qual os militantes de uma organização que defende a tendência retórica de enquadramento optam por um enquadramento baseado em molduras ideológicas em uma palestra geraram os artigos e as notícias publicados em jornais do estado do Rio Grande do Sul citados na introdução deste artigo ${ }^{12}$. No caso da notícia que retrata o outdoor em defesa de uma lei que proíba o trânsito de veículos de tração animal em Porto Alegre, a forma como operaram os mecanismos interativos reforçaram a preferência da organização que constrói esse material pela tendência retórica de enquadramento. A grande mídia e os governantes (alvo final da ação) são vistos como exemplos paradigmáticos de atores que não são influenciados por questões éticas, mas sim por alianças com as elites e por uma reprodução cotidiana da cultura vigente (atribuição de características ao interlocutor). Assim, ativistas antecipam um impacto negativo de uma crítica mais forte a práticas especistas que, ao mesmo tempo, são de grande importância cultural e econômica para o estado do Rio Grande do Sul. Porém, na medida em que a grande mídia e os governantes também são vistos como defensores do tradicionalismo, antecipa-se um impacto positivo de um argumento baseado na "tradição" (antecipação do impacto do enquadramento). A possibilidade de entrada apenas em um espaço padrão do jornalismo (a seção "Geral" do jornal) reforça ainda mais essas dinâmicas (situação de fala).

Já no caso do artigo publicado no jornal Zero Hora, no qual há uma crítica ao conceito de tradição, outro espaço do jornal é acessado. A seção de artigos permite, por um lado, que argumentos normalmente evitados por jornalistas possam ser publicados, na medida em que eles são associados a um terceiro que não está relacionado à empresa de comunicação. Por outro lado, esse espaço do jornal permite o desenvolvimento de uma argumentação mais abertamente posicionada, menos descritiva e mais abstrata (situação de fala). O acesso a esse espaço, no entanto, é restrito e depende de credenciais específicas. Nesse caso, a militante consegue acesso a esse espaço na medida em que apresenta credenciais formais, tais como o título de mestre em antropologia e de doutora em educação, e informais, tais como uma redação considerada satisfatória (desempenho de papel social). Essas e outras dinâmicas interativas reforçam, nesse caso, preferências prévias pela tendência conceitual de enquadramento.

Nesse ponto, é interessante comparar essa interação às situações de interação nas quais outra organização brasileira de defesa dos direitos animais, em geral, está inserida. Por se tratar de uma agência de notícias voltada à defesa dos direitos dos animais, os ativistas dessa organização, ao interagirem com a imprensa, se apresentam por meio do papel de jornalistas. Se o desempenho desse papel concede benefícios a esses ativistas (tais como o acesso privilegiado a grandes veículos de comunicação), esses benefícios só são assegurados se determinadas obrigações são cumpridas (desempenho de um papel social). Parte dessas obrigações está relacionada à adequação do material produzido pela agência de notícia às expecta- 
tivas que o meio jornalístico tem a respeito do trabalho desse tipo de organização, tais como a necessidade de manutenção de uma fala descritiva, a necessidade de abordar diversas temáticas, a necessidade de certificação das informações por fontes oficiais e a manutenção de uma alta taxa de produtividade (situação de fala). Dessa forma, ativistas dessa organização, apesar de procurarem manter seu enquadramento baseado em molduras ideológicas, se veem impossibilitados de apresentarem argumentos mais abstratos (como discussões filosóficas) ou abertamente posicionados. Assim, a utilização de molduras ideológicas é, nesse caso, mais tácita e menos abstrata se comparada ao que é observado no caso do artigo que critica a tradição gaúcha por meio de conceitos como especismo e senciência. São observadas, portanto, especificidades nos enquadramentos desenvolvidos em cada caso devido às peculiaridades das situações de interação, mesmo que, em ambos os casos, ativistas e organizações priorizem a mesma tendência de enquadramento.

Por fim, as características da interação na qual foi produzida a reportagem sobre veganismo no jornal Zero Hora também reforçaram as preferências identitárias prévias de alguns ativistas nela envolvidos. O caderno acessado do jornal é visto como espaço destinado à descrição de hábitos pessoais e não a discussões éticas aprofundadas. Nas palavras dos ativistas, encontravam-se nele "assuntos leves, para um caderno de domingo" (situação de fala). O temor que os ativistas relatam de que suas falas fossem distorcidas pela jornalista, conduzindo a matéria à reprodução de estereótipos, foi reduzido, na medida em que, segundo os ativistas, a repórter demonstrou interesse no assunto, não tendo feito perguntas baseadas em preconceitos e passando-Ihes a impressão (real, segundo a jornalista) de que uma pesquisa prévia sobre o tema havia sido feita (atribuição de características ao interlocutor). Na medida em que a profissional da mídia também relata que tinha maior interesse nos hábitos desses indivíduos e menos nas motivações que os levaram a adotá-los, intenções dos jornalistas e dos ativistas se combinaram (estabelecimento de intenções). Dessa forma, dinâmicas interativas reforçaram as preferências prévias dos atores.

Assim, é possível observar que, mesmo que ativistas e organizações de movimentos sociais tenham soluções preferenciais para o dilema do enquadramento, mecanismos interativos são decisivos para a definição das respostas efetivamente dadas. É provável, ainda, que ativistas e organizações busquem de forma mais ou menos intencional interações nas quais haja uma expectativa de reforço de suas preferências e, logo, maiores possibilidades de ação de acordo com as convicções previamente estabelecidas (Vaisey, 2008a). realizada em um município da Região Metropolitana de Porto Alegre, na medida em que não viam, nesse caso, possibilidades de obter, por meio da aliança com os atores presentes na interação, qualquer benefício para os animais. Dessa forma, a afirmação de que dinâmicas interativas podem obstaculizar preferências prévias carece de uma análise mais sistematizada que a suporte. A ausência dessa análise pode ser explicada por um problema metodológico de seleção dos casos. Após a primeira etapa de pesquisa, foram selecionados casos vistos como particularmente ilustrativos de determinada lógica de ação e de determinada "corrente" do movimento dos direitos animais. Dessa forma, observa-se uma tendência inicial gerada por esse critério de seleção de que os casos selecionados apresentassem reforços das dimensões interativas em relação às combinações preferenciais de lógicas de ação. 


\section{Considerações finais}

Este artigo buscou apresentar um novo modelo analítico para responder a dois problemas teóricos presentes na abordagem do enquadramento interpretativo. Como interpretar o dilema do enquadramento interpretativo? E como explicar as diferentes respostas de ativistas e organizações a um dilema comum?

Para a primeira dessas questões, o artigo buscou repensar e superar o esquema dicotômico que considera imperativos morais como "obstáculos" para a ação estratégica. Inspirando-se em Goffman (1986), foi proposta uma classificação baseada na adequação imaginada das molduras e no seu papel para organização da experiência dos atores. Foi possível assim, repensar o dilema do enquadramento em termos de um dilema entre diversas tendências de enquadramento que podem, todas elas, ser vistas como estratégicas e ideológicas.

Para a segunda dessas perguntas, um modelo de análise foi elaborado a partir da combinação de teorias nativas sobre a transformação social e pressões interativas (Figura 1). De acordo com este modelo de análise, ativistas e organizações de movimentos sociais desenvolvem diferentes teorias nativas sobre como a transformação

FIGURA 1

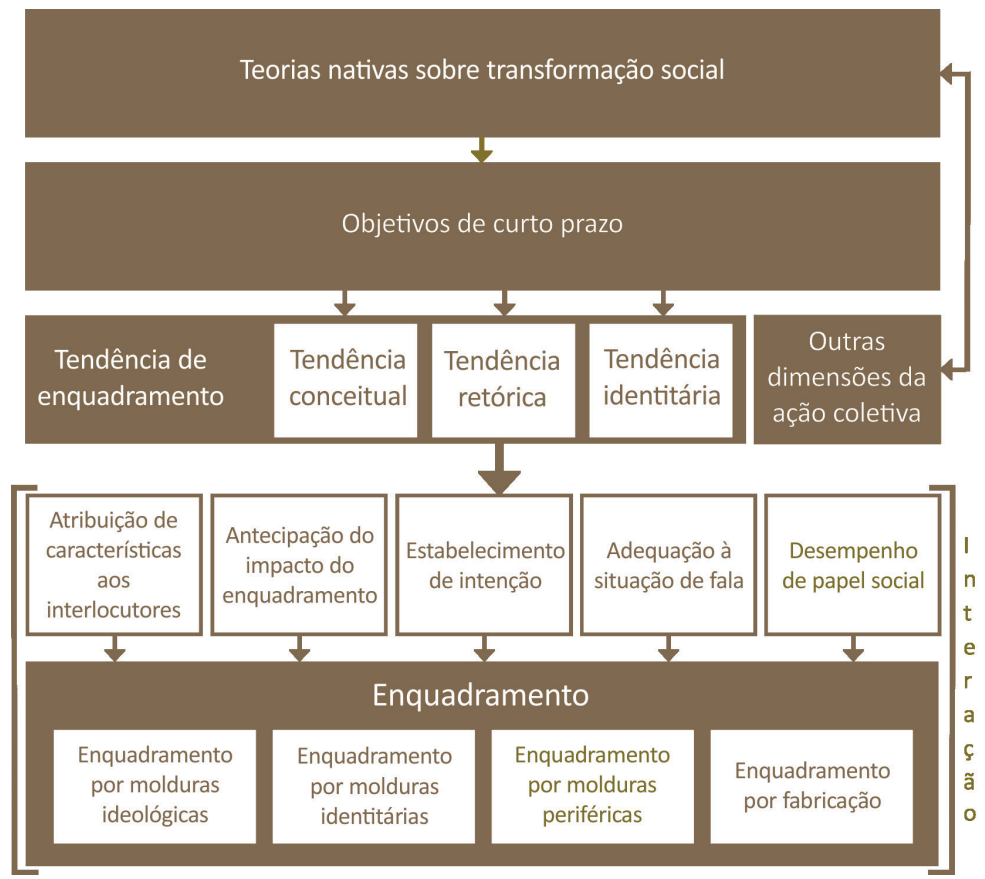


social ocorre. Cada teoria prioriza determinados objetivos que são mais facilmente atingidos por determinado tipo de tendência de enquadramento interpretativo, sendo geradas, assim, soluções preferenciais para o dilema do enquadramento interpretativo, vistas em todos os casos pelos atores como estratégicas e ideológicas. Mecanismos interativos contingentes, no entanto, incidem sobre tais respostas, podendo reforçar, obstaculizar ou especificar as preferências, moldando, assim as respostas efetivamente dadas ao dilema.

Como qualquer outro modelo compreensivo, o modelo analítico proposto apresenta lacunas. O movimento dos direitos animais, por exemplo, pode ser um caso em que esse dilema se apresente em uma configuração limítrofe, na medida em que suas molduras ideológicas se afastam radicalmente dos referenciais culturais dominantes. Ainda, esse modelo apresenta o viés cognitivista presente na literatura sobre enquadramento interpretativo, obscurecendo o papel das emoções para a definição de respostas aos dilemas (Goodwin, Jasper \& Polletta, 2001).

São necessários estudos que investiguem de forma mais aprofundada como dinâmicas interativas podem moldar preferências e disposições de ativistas. Ainda, essa investigação aponta para a necessidade de pesquisas sobre como indivíduos e organizações desenvolvem diferentes teorias sobre a transformação social. Por exemplo, como processos de socialização impactam a construção de tais teorias? E como identidades organizacionais ajudam a moldar (e são moldadas por) essas teorias? Por fim, na medida em que teorias da mudança social podem afetar outras escolhas táticas - como a escolha de arenas, alvos e repertórios -, pesquisas sobre o impacto de tais pressupostos tácitos nessas decisões e em processos como a polarização e a radicalização do confronto político também se mostram promissoras.

Abstract: Social movement activists face a dilemma in their framing activities. According to part of the literature, moral imperatives are constraints to strategic imperatives and this dilemma emerges from the tension between these poles. This paper has two objectives: (1) to question and to propose alternatives to the dichotomous characterization of the framing dilemma; (2) and to comprehend the processes that generate different solutions for this dilemma. To achieve these goals, we interviewed: leaders of four animal rights organizations of Porto Alegre; a leader of one organization of São Paulo; and activists and journalists involved in the production of news reports and articles selected for deeper analysis. Our data shows that moral and strategic imperatives are complementary and are generated by folk theories on social transformation and by interactive pressures, generating different solutions for the framing dilemma.

Keywords: framing; dilemma; social movements; animal rights; corporative media. 


\section{Referências}

ABONIZIO, Juliana. Consumo alimentar e anticonsumismo: veganos e freeganos. Ciências Sociais Unisinos, v. 49, n. 2, p.191-196, 2013.

ALMEIDA, Kamila. Sem carne no prato. Zero Hora, "Caderno Vida", p. 4-5, Porto Alegre, 2 Abr. 2011.

BATESON, Gregory. Steps to an ecology of mind. Collected essays in anthropology, psychiatry, evolution, and epistemology. Chicago: The University of Chicago Press, 1972.

BENFORD, Robert D. An insider's critique of the social movement framing perspective. Sociological Inquiry, v. 67, p. 409-430, 1997.

_ . "You could be the Hundreth Monkey": collective action, frames, and vocabularies of motive within the nuclear disarmament movement. The Sociological Quarterly, v. 34, n. 2, p. 195-216, 1993.

BENFORD, Robert D.; SNOW, David A. Framing processes and social movements: an overview and assesment. Annual Review of Sociology, v. 26, p. 611-639, 2000.

- Master frames and cycles of protest. In: MORRIS, A. D.; MUELLER, C. M. (Orgs.). Frontiers in social movement studies. New York: Yale University Press, 1992.

BENFORD, Robert D.; HUNT, Scott A. Dramaturgy and social movements: the social construction and communication of power. Sociological Inquiry, v. 62, n. 1, p. 36-55, 1992.

BERTONCELO, Edison Ricardo Emiliano. "Eu quero votar para presidente": uma análise sobre a Campanha das Diretas. Lua Nova, v. 76, p. 169-196, 2009.

CHERRY, Elizabeth. Veganism as a cultural movement. Social Movement Studies, v. 5, n. 2, p. 155-170, 2006.

CORREIO DO POVO. Pressão pelo fim das carroças, "Geral", p. 6. Porto Alegre, 16 Ago. 2008.

EVANS, Erin. Stumbling blocks or stepping stones? The problems and promises of policy reforms for animal rights advocacy movement. Sociological Perspectives, no prelo.

. Constitutional inclusion of animal rights in Germany and Switzerland: how did animal protection become an issue of national importance?. Society and Animals, v. 18, p. 231-250, 2010. 
FRANCIONE, Gary. Reflections on "animals, property and the law" and "rain without thunder". Law and Contemporary Problems, v. 70, n. 1, p. 9-57, 2007.

FREEMAN, C.P. Framing animal rigths in the "Go Veg" Campaigns of U.S. Animal Rights Organizations. Society \& Animals, v. 18, n. 2, p.163-182, 2010.

GAMSON, William. Goffman's legacy to political sociology. Theory and Society, v. 14, n. 5, p. 605-622, 1985.

GAMSON, William; MODIGLIANI, Andre. Media discourse and public opinion on nuclear power: a constructionist approach. American Journal of Sociology, v. 95, n. 1, p. 1-37, 1989.

GAMSON, William; FIREMAN, Bruce; RYTINA, Steven. Encounters with unjust authorities. Illinois: The Dorsey Press, 1982.

GARNER, Robert D. Defending animal rigths. Parliamentary Affairs, v. 51, n. 3, p. 458-469, 1998.

GILL, Rosalind. Análise de discurso. In: BAUER, M. W.; GASKELL, G. (Orgs.). Pesquisa qualitativa com texto imagem e som: um manual prático, p. 244-270. Petrópolis: Vozes, 2002.

GILLAN, Kevin. Understanding meaning in movements: a hermeneutic approach to frames and ideologies. Social Movement Studies, v. 7, n. 3, p. 247-263, 2008.

GOFFMAN, Erving. A representação do Eu na vida cotidiana. Petrópolis: Vozes, 2002.

- Frame analysis: an essay on the organization of experience. Boston: Northeastern University Press, 1986.

GOODWIN, Jeff; JASPER, James M; POLLETTA, Francesca. Introduction: why emotions matter? In: GOODWIN, Jeff; JASPER, James M; POLLETTA, Francesca (Orgs.). Passionate politics: emotions and social movements. Chicago: University of Chicago Press, 2001.

HASSEN, Maria de Nazareth Agra. Gaúchos amam e maltratam os animais. Zero Hora, "Tema para Debate", p. 17, Porto Alegre, 12 Set. 2010.

HEWITT, Lyndi; McCAMMON, Holly J. Explaining suffrage mobilization: balance, neutralization, and range in collective action frames. In: JOHNSTON, H.; NOAKES, J. A. (Orgs.). Frames of protest: social movements and the framing perspective. Lanham: Rowman Littlefield, 2005. 
JASPER, James M. The art of moral protest. Chicago; London: The University of Chicago Press, 1997.

JASPER, James M.; POULSEN, Jane D. Recruiting strangers and friends: moral shocks and social networks in animal rights and anti-nuclear protests. Social Problems, v. 42, n. 4, p.493-512, 1995.

JOHNSTON, Hank. Comparative frame analysis. In: JOHNSTON, H.; NOAKES, J. A. (Orgs.). Frames of protest: social movements and the framing perspective. Lanham: Rowman Littlefield, 2005.

JOHNSTON, Hank. A methodology for frame analysis: from discourse to cognitive schemata. In: JOHNSTON, H.; KLANDERMANS, B. Social movements and culture: social movements, protest and contention, v. 4. Minneapolis: University of Minnesota Press, 2000.

JOHNSTON, Hank; ALIMI, Eitan Y. A methodology analyzing for frame dynamics: the grammar of Keying Battles in Palestian Nationalism. Mobilization: An International Quarterly, v. 18, n. 4, p. 453-474, 2013.

- Primary frameworks, keying and the dynamics of contentious politics: the islamitzation of Chechen and Palestinian National Movements. Political Studies, v. 60, p. 603-620, 2012.

JOHNSTON, H.; NOAKES, J. A. (Orgs.). Frames of protest: social movements and the framing perspective. Lanham: Rowman Littlefield, 2005.

JOHNSTON, Hank; OLIVER, Pamela. Breaking the frame. In: JOHNSTON, H.; NOAKES, J. A. (Orgs.). Frames of protest: social movements and the framing perspective. Lanham: Rowman Littlefield, 2005.

LUZ, Loraine. Como ser vegano na terra do churrasco. Zero Hora, "Caderno Donna", p. 10-15, Porto Alegre, 5 Jun. 2011.

MACIEL, Débora Alves. Ação coletiva, mobilização do direito e instituições políticas: o caso da Campanha da Lei Maria da Penha. Revista Brasileira de Ciências Sociais, v. 26, n. 77, p. 97-111, 2011.

MAIA, Rousiley C. M. Atores da sociedade civil e ação coletiva: relações com a comunicação de massa. Lua Nova, v. 76, p. 87-118, 2009.

MATHIEU, Lilian. Rapport au politique, dimensions cognitives et perspectives pragmatiques dans l'analyse des mouvements sociaux. Revue Française de Science Politique, v. 52, n. 1, p. 75-100, 2002. 
McADAM, Doug. Marcos interpretativos culturales y táticas utilizadas por los movimientos: dramaturgía estratégica en el Movimiento Americano Pro-Derechos Civiles. In: McADAM, D.; MORRIS, J. D.; ZALD, M. N. (Orgs.). Movimientos sociales - perspectivas comparadas, p.475-194. Madrid: Istmo, 1999.

Political process and the development of black insurgency. Chicago: University of Chicago Press, 1982

McADAM, Doug; TARROW, Sidney; TILLY, Charles. Dynamics of contention. Cambridge: Cambridge University Press, 2001.

McADAM, Doug; McCARTHY, John D.; ZALD, Mayer N. (Orgs.). Movimientos sociales - perspectivas comparadas. Madrid: Istmo, 1999.

McCAMMON, Holly J. Beyond frame resonance: the argumentative structure and persuasive capacity of Twentieth-Century U.S. Women's Jury Rights Frames. Mobilization: An International Journal, v. 14, n. 1, p.45-64, 2009.

MELUCCI, Alberto. The process of collective identity. In: JOHNSTON, H.; KLANDERMANS, B. Social movements and culture: social movements, protest and contention, v. 4. Minneapolis: University of Minnesota Press, 2000.

- The process of collective identity. In: JOHNSTON, Hank; KLANDERMANS, Bert (Orgs.). Social movements and culture: social movements, protest, and contention (vol. 4), p. 41-63. Minneapolis: University of Minnesota Press, 1995.

NACONECY, Carlos. Bem-estar animal ou libertação animal? Uma análise crítica da argumentação antibem-estarista de Gary Francione. Revista Brasileira de Direito Animal, v. 4, n. 5, p. 235-267, 2009.

NOAKES, John A.; JOHNSTON, Hank. Frames of protest: a road map to a perspective. In: JOHNSTON, H.; NOAKES, J. A. (Orgs.). Frames of protest: social movements and the framing perspective. Lanham: Rowman Littlefield, 2005.

NUNES, Jordão Horta. Frame e identidade coletiva: uma perspectiva interacionista de análise dos movimentos sociais. Contemporânea, v. 3, n. 1, p. 143-172, 2013a.

- Interacionismo simbólico e movimentos sociais: enquadrando a intervenção. Revista Sociedade e Estado, v. 28, n. 2, p. 257-277, 2013b.

OLIVER, Pamela E.; JOHNSTON, Hank. "What a good idea! Ideologies and frames in social movement research". In: JOHNSTON, H.; NOAKES, J. A. (Orgs.). Frames of protest: social movements and the framing perspective. Lanham: Rowman Littlefield, 2005. 
PENNA, Camila. Poder simbólico e protesto: uma análise das representações dos governos brasileiros e argentinos sobre as ações do MST e do movimento piquetero. Espacio Abierto - Cuaderno Venezolano de Sociología, v. 21, n. 3, p. 423-451, 2012.

PEREIRA, Matheus M. Enquadramento interpretativo, lógicas de ação e dinâmicas interativas: dilemas em interações entre o movimento dos direitos animais e a grande mídia. Dissertação (Mestrado em Sociologia) - Universidade Federal do Rio Grande do Sul, Porto Alegre, 2014.

POLLETA, Francesca. Culture in and outside institutions. Research in Social Movements, Conflicts and Change, v. 25, p. 161-183, 2004.

- Culture and its discontents: recent theorizing on the cultural dimensions of protest. Sociological Inquiry, v. 67, n. 4, p. 431-450, 1997.

PRUDENCIO, Kelly Cristina de Souza; SANTOS, Jocelaine Josmeri dos. Mídia e movimentos sociais: um esboço metodológico a partir da frame analysis de Erving Goffman. Trabalho apresentado no IV Encontro da Compolítica, Universidade do Estado do Rio de Janeiro, 13 a 15 de abril de 2011.

ROHLINGER, Deana A. Framing the abortion debate: organizational resources, media strategies, and movement-countermovement dynamics. The Sociological Quarterly, v. 43, n. 4, p. 479-507, 2002.

ROTHBERG, Danilo; BERBEL, Danilo Brancalhão. Enquadramentos de transgênicos nos jornais paulistas: informação como potencial subsídio à participação política. História, Ciências, Saúde - Manguinhos, v. 17, n. 2, p. 455-470, Abr.-Jun. 2010.

SILVA, Marcelo K.; COTANDA, Fernando C.; PEREIRA, Matheus M. Interpretação e ação coletiva: o enquadramento interpretativo. Revista de Sociologia e Política, no prelo.

SNOW, David A. Framing processes, ideology, and discursive fields. In: SNOW, D. A.; SOULE, S.; KRIESI, H. The Blackwell Companion to social movements. Oxford: Blackwell Publishing, 2004.

SNOW, David A.; BENFORD, Robert D.; McCAMMON, Holly J.; HEWITT, Lyndi; FITZGERALD, Scott. The emergence, deveplopment, and future of the framing perspective: 25 + years since "frame alignment". Mobilization: An International Quarterly, v. 19, n. 1, p. 23-45, 2014.

SNOW, David A.; BENFORD, Robert D. Clarifying the relationship between framing and ideology. In: JOHNSTON, H.; NOAKES, J. A. (Orgs.). Frames of protest: social movements and the framing perspective. Lanham: Rowman Littlefield, 2005. 
SNOW, David A.; BENFORD, Robert D. Ideology, frame ressonance and participant mobilization. International Social Movements Research, v. 1, p. 197-218, 1988.

SNOW, David A.; BYRD, Scott. Ideology, framing processes, and the islamic terrorist movements. Mobilization: An International Journal, v. 12, p. 119-136, 2007.

SNOW, David A.; ROCHFORD JR., E. Burke; WORDEN, Steven K.; BENFORD, Robert D. Frame alignment processes, micromobilization, and movement participation. International Social Movement Research, v. 51, n. 4, p. 464-481, 1986.

SNOW, David A. Framing processes, ideology, and discursive fields. In: SNOW, D. A.; SOULE, S.; KRIESI, H. (Orgs.). The Blackwell Companion to Social Movements. Oxford: Blackwell Publishing, p.205-211, 2004.

SORDI, Caetano. O animal como próximo: por uma antropologia dos movimentos de defesa dos direitos animais. Cadernos IHU Ideias, Ano 9, n. 147, 2011.

STEINBERG, Marc W. Tilting the frame: considerations on collective action framing from a discursive turn. Theory and Society, v. 27, p. 845-872, 1998.

STZYBEL, David. Animal rights law: fundamentalism versus pragmatism. Journal for Critical Animal Studies, v. 5, Issue 1, p. 1-35, 2007.

SWIDLER, Ann. Culture in action: symbols and strategies. American Sociological Review, v. 51, n. 2, p. 273-286, 1986.

SWIDLER, Ann. Comment on Stephen Vaisey's Socrates, Skinner, and Aristotle: three ways of thinking about culture in action. Sociological Forum, v. 23, n. 3, p.614-618, 2008.

TARROW, Sidney. O poder em movimento: movimentos sociais e confronto politico. Petrópolis: Vozes, 2009.

VAISEY, Stephen. Socrates, Skinner, and Aristotle: three ways of thinking about culture in action. Sociological Forum, v. 23, n. 3, p. 603-613, 2008a.

VAISEY, Stephen. Reply to Ann Swidler. Sociological Forum, v. 23, n. 3, p. 619-622, 2008b.

WESTBY, David L. Strategic imperative, ideology and frames. In: JOHNSTON, H.; NOAKES, J. A. (Orgs.). Frames of protest: social movements and the framing perspective. Lanham: Rowman Littlefield, 2005. 
ZHAO, Dingxin. Theorizing the role of culture in social movements: illustrated by protests and contentions in Modern China. Social Movement Studies, v. 9, n. 1, p. 33-50, 2010. 